\title{
Disorders characterised by pain: a methodological review of population surveys
}

\author{
Heiner Raspe, Thomas Kohlmann
}

\begin{abstract}
Objective - To review a series of conceptual and methodological problems encountered in surveys primarily devoted to pain disorders.

Criteria for inclusion and exclusion of articles - Published reports were systematically collected by electronic database searches (Medline), citations in existing publications, and through personal contacts. Relevant articles from clinical and epidemiological research on pain were included and special attention was given to epidemiological research on back pain.
\end{abstract}

Conclusions - Surveys of pain disorders should be based on a multidimensional pain model that includes nociceptive input, pain perception, suffering, and pain behaviour as major components. Because of the limited applicability of diagnostic procedures or genuine "non-specificity" of pain states, or both, epidemiological surveys may result in a considerable proportion of cases without an identifiable pathophysiological basis. Staging and grading procedures for pain disorders (as distinguished from classification) may comprise various aspects of pain perception: regional distribution, pain intensity, temporal characteristics, sensory qualities, and dimensions of cognitiveemotional appraisal. Description of temporal development and chronification (staging) should refer to different components of the multidimensional pain model. Explicit a posteriori procedures for grading are preferable to implicit grading based on question wording. Evidence from several sources suggests that localistic concepts of pain may be misleading. Identification of complex pain syndromes should be one primary target for epidemiological pain surveys. Of the many factors that may impair the reliability and validity of data collected in pain surveys, recall biases seem to deserve special attention.

\section{( $\mathcal{F}$ Epidemiol Community Health 1994;48:531-537)}

The first survey devoted exclusively to the assessment of multiple sources of pains was pub- lished in 1984 by a Canadian group, ${ }^{1}$ and the number of subsequent studies has been surprisingly small. ${ }^{2-7}$ Surveys focussing on site or system specific pain, however, have a longer tradition. The first epidemiological survey on musculoskeletal pain was conducted in the late $1950 \mathrm{~s}$ in the UK. ${ }^{8}$ Surveys of (chronic) pain face many problems, both conceptual and technical. ${ }^{9}$ Many of these problems have become evident from surveys of back pain, and indeed this site has been studied for longer and in more detail than any other type of pain (see $e^{10}$ for review). Thus, experience from back pain surveys will be used to clarify the scope and nature of these problems. This review concentrates primarily on concepts and methods and less on a detailed description of results from previous studies: it attempts to reach practical conclusions and recommendations for future epidemiological surveys of painful disorders.

Which dimensions of pain should be measured?

The International Association for the Study of Pain (IASP) defined pain as "an unpleasant sensory and emotional experience associated with actual or potential tissue damage, or described in terms of such damage". ${ }^{11}$ Even superficial recall of a simple pain experience, such as touching a red hot object, reveals its complex nature. Thus, in addition to the description of pain in terms of spatial and temporal characteristics, other facets are of relevance, including: severity, sensory impressions (such as "burning") and distinct cognitive ("why me again?"), emotional ("horrible"), behavioural (flight, then cooling), and somatic (sweating, increased heart rate) phenomena.

One useful model of different components of pain is that of Loeser ${ }^{12}$ (fig 1), which includes four dimensions: nociception, pain, suffering, and pain behaviour. In Loeser's model, "pain" is defined as "the perception of a nociceptive input to the nervous system". "Suffering" refers to the "negative affective response generated in the higher nervous system by pain", whereas "pain behaviour" is meant to denote "any type of output from the organism that is commonly understood to suggest the existence of a tissuedamaging stimulus".

In contrast to the physiological and clinical 


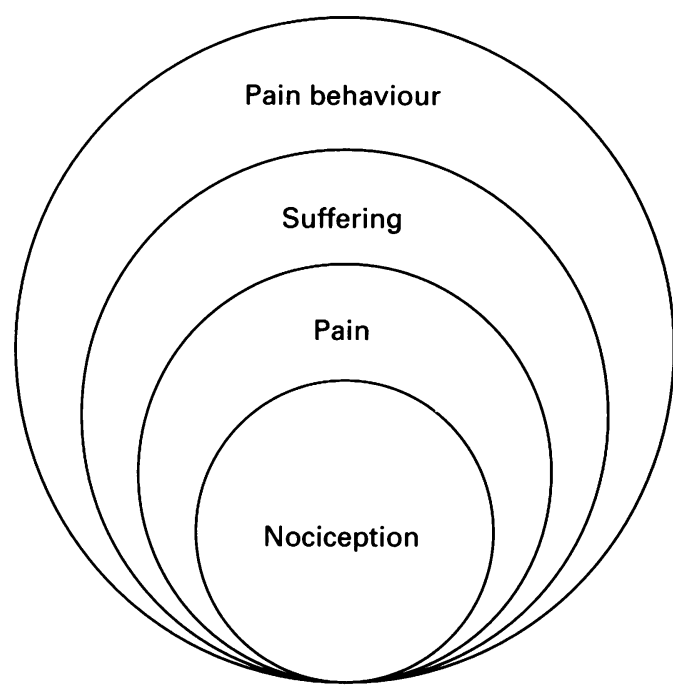

Figure 1 Loeser's multifaceted model of the components of pain. $^{12}$

concerns about a specific somatic problem involving nociception, behavioural scientists and epidemiologists are constrained by having to start inductively with the assessment of pain reporting behaviour - for example, recording a "yes" or "no" to the question "do you have back pain today?". Thus, epidemiologists concentrate primarily on the most non-specific component of pain biomedically: subjects with totally heterogeneous chronic pain disorders may show very similar pain behaviour patterns.

\section{Problem of "non-specific" pain}

If the aetiopathogenesis of a pain state cannot be identified after a selected set of simple examination techniques such as history taking, psychiatric interview, clinical examination, basic blood tests, and conventional $x$ rays have been done it is usually described as "nonspecific" or "idiopathic". As a consequence, although it seems comparatively easy to collect information on pain related behaviour, affects, and perceptions, it is much more difficult in surveys to address clinically the supposed underlying physical problem(s). The days when participants of epidemiological studies could easily be subjected to $x$ rays and other potentially hazardous diagnostic tests have (fortunately) gone. Examination surveys have basically to rely on a sound clinical examination, which is necessary but insufficient to explain the differential diagnosis of back pain and other painful disorders.

Even more invasive diagnostic measures, however, have their limits. In one German study $^{13}$ of 104 carefully and extensively investigated (for example, by discography) back pain patients referred to a university pain clinic, no medical diagnosis could be made for 35 . This suggests that the proportion of subjects with "non-specific" pain is a function of both the degree of diagnostic assessment and of the nature of the disorder.

What is the appropriate level of investigation in surveys? Since no epidemiological study will solve the enigma of non-specific pain in general, it seems more useful to concentrate on a few selected conditions than to use a wide range of unselective examinations with no clear target. The ultimate answer depends critically on the research question: an aetiologically oriented study has to specify its target condition(s) as strictly and narrowly as possible, whereas a study that analyses the health care usage of back pain sufferers or the reactions of primary care physicians can concentrate solely on the symptom.

\section{Classification of pain states}

Given the heterogeneity of most painful disorders it is generally useful to classify cases ascertained. In medicine, "classification" refers to the assignment of cases or patients to predefined groups ("species") within a taxonomy of entities. Ideally, each entity should show an identical clinical appearance, pathophysiology, course, prognosis, and therapeutic response, and the taxonomy should have an aetiopathogenetical basis. In practice, such a system does not and probably will never exist. This is particularly true for heterogeneous disorders such as back pain, and a number of different schemes has been proposed. ${ }^{14-19}$

In one approach, Talo et $a l^{20}$ subjected a set of psychological variables to cluster analysis and, using a concept proposed by Turk and Rudy, ${ }^{21}{ }^{22}$ identified three classes of back pain patients - "interpersonally distressed", "adaptive copers", and "dysfunctional patients". The distress and risk assessment method ${ }^{23}$ offers a related classification of low back pain patients based on four variables, which can, in principle, be applied within an epidemiological study. These are two psychological variables "modified somatic perception" 24 and a depression score, and the presence of "non-organic signs" 25 and "inappropriate symptoms". ${ }^{26}$ Subjects are assigned to four groups - those showing "no psychological distress", those "at risk of developing major psychological overlay", "distressed-depressive", and "distressed-somatic".

An alternative approach to classification systems based on manifestations of back pain is to distinguish between specific and non-specific back pain as defined earlier. The International Classification of Diseases (ICD) in its 9th and 10 th revisions, may be used as a catalogue of disorders and diseases predisposing to back pain, for instance, deforming dorsopathies, inflammatory spondylopathies, intervertebral disc disorders. Different sets of classification criteria are now available to identify some of them as, for example, a group of spondylarthropathies ${ }^{27}$ or the fibromyalgia syndrome. ${ }^{28}$ By contrast there are no accepted classification schemes based either on pathological processes or the anatomical structures thought to be involved.

Non-specific back pain could be further subclassified in terms of its manifestation, for instance as purely organic, almost purely organic, mixed, or purely psychiatric, as suggested on the basis of a standardised medical and psy- 
chiatric examination of clinical back pain patients. ${ }^{29}$ The heterogeneity of the different approaches is striking, and surprisingly, so far only few have been tested in population studies.

Whereas "classification" relies on a system of fixed nominal classes or types of pain, and "staging" implies a temporally dynamic concept of a developmental process, "grading" refers to an ordinal scale with different levels of severity independent of class or stage. The basis for staging and grading are variables derived from an analysis of the perception of (back) pain (see below).

\section{Dimensions of pain perception}

Four important structural dimensions will be considered here: regional distribution, intensity, temporal characteristics, and sensory qualities including cognitive and emotional appraisal. All are, as exclusively subjective phenomena, accessible in questionnaire and interview surveys.

\section{REGIONAL DISTRIBUTION}

Population based surveys usually rely on verbal descriptions of painful sites (such as back pain, chest pain, facial pain) or organs (as joint pains, muscle pains), leaving the decision on where to locate the back, for example, entirely to the respondents. Recent studies offer region of interest (ROI) drawings or complete pain mannequins in which the affected regions can be marked (fig 2). ROI drawings are obviously useful but still lack standardisation. Thus, the recently completed East German Health Survey used a drawing that covered the total area below $\mathrm{C} 7$ and the gluteal folds (fig 2, right). An English version (fig 2, left) followed a medical definition of the low back - that is, the area "between the lower costal margins and the gluteal folds". 1530 The Standardised Nordic questionnaire for the analysis of musculoskeletal symptoms ${ }^{31}$ (fig 2, middle) presents an even smaller region. How the different definitions match with the subjective body concepts of lay persons is unknown.

In clinical populations, it has been found that pain drawings using an outline of a human body on to which patients mark the painful areas allow the identification of the spatial dis-
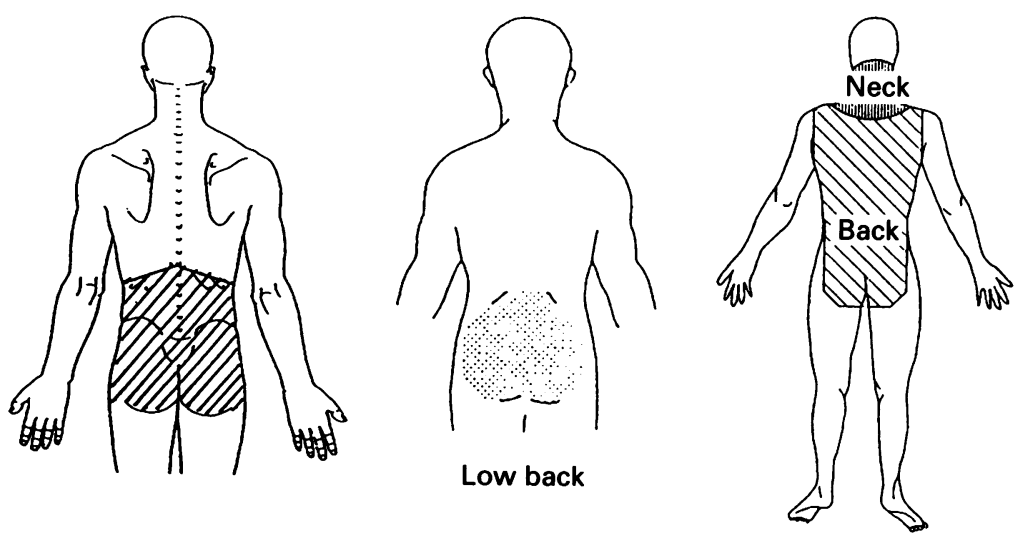

Figure 2 Region of interest drawings and pain mannequins in back pain research. tribution of pain. ${ }^{32-34}$ In addition they may support a gross estimate of its organic versus its non-organic nature ${ }^{35-37}$ and predict poor treatment outcome. ${ }^{38}$ However, their usefulness in identifying patients whose pain has a "psychological overlay" $39-41$ has not been unequivocally supported. ${ }^{42-44}$ The advantage of pain drawings (compared with ROI drawings) is that they allow the researcher to apply different definitions of "the back", to compare these with verbal responses, and to identify pain patterns affecting several and possibly distant regions. The pain can then be rated as monotopical, oligotopical, polytopical, or wide-

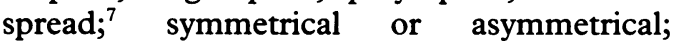
periarticular or axial; etc. This promising technique has not been widely used in pain surveys and its validity and reliability have to be studied further. ${ }^{75}$

\section{PAIN INTENSITY}

Different techniques have been adopted for measuring pain intensity, with visual analogue scales and verbal or numerical rating scales being most often used in clinical pain research and in pain surveys. Comparative studies have shown that different methods of measurement yield similar results. In practice, visual analogue scales seem to be more difficult to understand by respondents. ${ }^{46-49}$ Verbal rating scales (for example, "almost imperceptible", "like wearing tight clothes", "like being stiff after exercise", etc. ${ }^{4}$ ) might work well in one country but might be difficult to translate into other languages. We therefore use and recommend numerical rating scales (for example an 11 point scale anchored at "no pain" $=0$ and "intolerable pain" =10) which have been successfully applied (with slight modifications) to pain surveys (for example ${ }^{250}$ ).

\section{TEMPORAL CHARACTERISTICS}

Assessing temporal characteristics of pain perception is a highly complex matter: the duration and frequency of episodes as well as acuteness of and time since onset are relevant parameters of the temporal structure of pain. No general framework for its measurement has been developed so far. The most simple question seems to be that for present pain: "do you have (back, head, neck etc) pain today". Under certain assumptions, it leads to an estimate of point prevalence. Less simple questions refer to the duration of the actual episode: "for how many days without interruption have you had these back pains, that is without one or several days free of pain?"51 or to the number of days in pain: "on roughly how many days (if any) in the past 12 months have you had that type of pain?". ${ }^{2}$ Retrospective questions may differ in the time frame they use ("pain during past... days/weeks/months" or "ever"). Other questions may clarify the longitudinal pattern (for example, episodic, intermittent, recurrent, persistent), the general trend (increasing/decreasing within the last year), or age at and mode of first manifestation (acute or slow). 
SENSORY QUALITIES AND COGNITIVE-AFFECTIVE CHARACTERISTICS

Sensory qualities and characteristics of the cognitive and affective appraisal have been studied in numerous clinical samples of patients suffering from chronic pain disorders. Evidence of the usefulness of particular measures in epidemiological studies is lacking. The McGill pain questionnaire (MPQ) is probably the most widely used instrument for the assessment of sensory, affective, and evaluative dimensions of pain. ${ }^{52-54}$ Yet its discriminant validity (even in a clinical context) has been questioned in a recent multicentre evaluation study. ${ }^{55}$ Specific scales for the measurement of pain related coping strategies, ${ }^{56-57}$ pain related cognitions and self statements, ${ }^{58}$ or pain locus of control ${ }^{5960}$ have been developed for use in clinical samples, but have not yet been included in population based (back) pain surveys.

\section{Staging of pain and defining chronicity}

Staging is widely used in clinical medicine and is based on a temporally dynamic model of developmental processes with identifiable stages to which cases can be assigned. In pain research, a basic distinction is made between acute, subacute, and chronic pain. Pain is arbitrarily and variably defined as acute if it is present for less than six weeks, ${ }^{30}$ though others adopt limits of three ${ }^{15}$ or even six months. ${ }^{11}$ Subacute pain is said to last between six weeks and six months, ${ }^{40}$ whereas chronic pain has to persist for more than six months. ${ }^{1161}$

This confusion is only increased by defining chronic pain in terms of its persistence beyond what is deemed a normal healing time. ${ }^{62}$ This definition focusses on the supposed physical basis. of the problem and seems unable to differentiate adequately between chronic pains with ongoing nociceptive input and those in which persistent noxious stimuli and chronic nociception cannot be identified. To clarify this issue, different aspects of chronicity, each with its own determinants and temporal requirements, can be distinguished, based on the separate features of the physical problem/ nociception, pain perception, suffering, and pain behaviour. ${ }^{12} \mathrm{~A}$ fifth aspect may be added: the social consequences of pain. ${ }^{63}$ An appropriate temporal definition of acute versus chronic can then be used for each of the five levels. As an example, the Quebec Task Force ${ }^{61}$ has defined activity related back pain as chronic if absence from work exceeds more than seven weeks. This model may also be helpful in developing a more detailed understanding of chronicity or "augmentation" of pain problems. The idea of augmentation has given rise to the concept of chronic "dysfunctional" pain, ${ }^{21}$ which is not only persistent or recurrent but is regularly accompanied by an augmentation process with a (possibly distinct) sequence of cognitive, affective, and behavioural changes.

At present a simple temporal definition, which retrospectively assesses the duration of the actual (however multifaceted) pain episode, seems preferable. The identification of the total disease duration since first onset is less useful.
Thus, in Germany, the lifetime prevalence of back pain reaches nearly $90 \%$ in subjects aged 25 to $29^{10}$ and even more than $40 \%$ of 12 year old schoolchildren report back pain. ${ }^{64}$

\section{Implicit and explicit grading of back pain} Some grading system for back pain is necessary given its frequency in the general population. In West Germany for instance its point prevalence presently reaches $40 \%$, its one year prevalence $70 \%$, and its lifetime prevalence exceeds $80 \%{ }^{10}$ Its severity, however, varies within a wide range between hardly perceptible and intolerable, disabling pain.

Each back pain survey has used an idiosyncratic key question, mostly with a temporal or an intensity restriction, or both - that is with an implicit grading (and/or staging). Some examples may illustrate this: The US National Health and Nutrition Examination Survey (NHANES-1) identified subjects with back and other types of pain only if they had suffered from it "most days for at least 1 month in the 12 months preceding the interview". ${ }^{65}$ The NHANES II survey enquired about "pain in your back on most days for at least 2 weeks" ever. ${ }^{66}$ To be included in further analyses, respondents to the Puget Sound Study in western Washington State ${ }^{3}$ had to report pain "that had lasted a whole day or more, or that had occurred several times in a year". The Canadian Household Survey ${ }^{1}$ aimed at identifying subjects who were "often troubled with pain". In a recent British study only low back pain which, "lasted for more than 24 hours and which was not associated exclusively with febrile illness, menstrual periods, or pregnancy" was recorded. ${ }^{67}$ There are, however, screening questions which are less specific. In a Danish study ${ }^{68}$ respondents were asked: "Have you ever/within the last 12 months experienced pain or other symptoms in the lower part of your back?". The corresponding question in The British Health and Lifestyle Survey was: "Within the last month have you suffered from any problems with a bad back?". ${ }^{69}$ In three recent studies the authors have used as a first postal screening question: "Do you have back pain today?". ${ }^{51}$

This diversity makes it probable that different surveys cover different parts of the total severity spectrum of back pain and hence explain, at least partly, some of the variation in reported prevalence rates. This unsatisfactory situation could be overcome if different groups either used an identical implicit grading system (which is unlikely to be achieved) or employed a comparably sensitive baseline question which would permit a post hoc explicit grading. Various post hoc grading procedures have been proposed, ${ }^{407071}$ each of which is based on different concepts. Some ${ }^{5071}$ were derived using strict psychometric criteria and were thoroughly tested in epidemiological studies. The authors ${ }^{51}$ applied two basic dimensions of such a model and produced a simple scheme for grading current pain status of subjects with back pain by using current intensity (measured by a 10 point numerical rating scale) and current functional limitations in everyday life 
assessed by a short, back pain-specific questionnaire (ADL list). Back pain cases were assigned to one of three ordered categories.

Other approaches to grading could be based on the temporal characteristics of the index episode, ${ }^{50}$ the level of concomitant symptoms (see below), and variables that reflect the pain related cognitive and emotional appraisal. The development of a more complex grading system, however, is a time consuming project, the additional benefit of which may be questioned

\section{Localised pain as part of a wider complaint syndrome}

Most site specific pain surveys have neglected the importance of concomitant symptoms. These single-site focussed, questionnaire/interview techniques are blind to the fact that perhaps most types of pain are likely to be part of complex complaint syndromes.

This can best be illustrated with results from pain surveys: The Nuprin Pain Report enquired about the occurrence of seven distinct types of pain within the past year. Only $10 \%$ of all subjects with pain in the back had experienced back pain only, whereas $90 \%$ reported (unspecified) combinations of back and other pains. ${ }^{2}$ In the Puget Sound Study, $47 \%$ of the pain subjects recorded simultaneous pains in two or more (of a total of five listed) sites. ${ }^{72}$ Similar results have been found in other surveys. ${ }^{43}$ Most recently, these results have been extended by showing a close association between chronic, widespread pain and a number of somatic and affective symptoms. ${ }^{7}$ In one postal survey, $31 \%$ of 4037 German residents of Hannover, Germany, aged 25 to 74 had back pain "today" of whom $81 \%$ suffered from neck pain, joint pain, morning stiffness and/or subjective swelling around joints simultaneously. In another German postal survey, these pain/complaint patterns were investigated more systematically: ${ }^{75}$ The pain questionnaire was accompanied by a validated German symptom check list with 24 items ${ }^{76}$ and a score range from 0 to 72 . Among people who reported current back pain, the mean symptom score (adjusted for age and sex) was 22.5 (95\% CI, $21.0,24.4$ ) compared with a score of 13.4 for those with no back pain "today" and 5.6 for the small subgroup who reported never having had back pain. Subjects with back pain had significantly higher scores for 23 of the 24 items, notably for tired legs, dyspnoea, restless legs, vertigo, and fatigue.

In summary, these results suggest that the concept of "regional back pain"77 may be questioned: back pain seems to imply more than pain in the back!

\section{Sampling and non-sampling errors}

Finally, it is important to consider the impact of a great variety of potential biases on pain surveys. These may be attributable to characteristics of the respondents, the interviewer, or the method used for data collection. ${ }^{78-81}$

The necessity for systematic investigation is obvious from the many problems discussed earlier as well as from a range of counter intuitive results in virtually any back pain survey (see ${ }^{10}$ for more details). Three prominent examples were:

(1) In several studies the prevalence of current and past back pain (of all grades combined) shows a distinct "paradoxical" age pattern, with a peak around the age of 60 and a decrease among the elderly. ${ }^{6673} \mathrm{We}$ and others ${ }^{2}$ have observed, even more surprisingly, a peak in one year and/or lifetime prevalence among the youngest. In contrast, severe back pain usually follows a pattern with an increasing prevalence and a peak in the highest age group. ${ }^{5167}$

(2) The curves for the age specific, one-year and lifetime prevalence rates run, on a different level but strictly parallel; the difference between the two is often around or less than $10 \%{ }^{66-68}$

(3) Incidence estimates derived from cross sectional and cohort studies lead to incredible results: Valkenburg and Haanen, ${ }^{73}$ for instance, reported incidence rates of "some $11 \%$ annually" in their youngest age group (20-25 years) with a decrease to $2 \%$ in the highest; Biering-Soerensen ${ }^{68}$ recorded an annual incidence rate of even $17 \%$. However, any rate above $4 \%$ seems implausible.

It is still not clear which of these results has a plausible explanation for which specific sampling and non-sampling errors can be identified. Firstly, all population based back pain studies suffer from incomplete response, mostly in the range of $15 \%$ to $30 \%$. Thus, selection biases might be in effect. Secondly, most relevant surveys of pain, and specifically back pain, have used retrospective reports of past pain experiences. The accuracy of retrospective reports of episodes of pain depends on the respondent's ability to recall the episode, to date it with sufficient precision, and to recall its intensity, duration, and other qualities. Memory decay, "telescoping", and additional response errors can introduce considerable recall biases. ${ }^{92}$ Factors which have been found to contribute to recall bias are characteristics of the actual pain experience, time interval and degree of detail, significance of events, personal (for example, sociodemographic) characteristics of the respondent, and interviewing technique. ${ }^{83}$ There have recently been very promising approaches to studying the general problem of "memory for health related events" from a social cognition perspective. ${ }^{84-86}$ In the epidemiology of back pain, it is generally assumed that more recent episodes are recalled better than earlier events and that the same holds true for more severe (versus mild) episodes. ${ }^{10}$ Recall bias in inteview data of the incidence and prevalence of back pain can be illustrated by the results of Westrin, ${ }^{87}$ who compared work incapacity data held by the General Sickness Insurance in Gothenburg with self reported sick listing because of low back pain. For a 12 year period, the self report data showed comparatively good reliability. Under-reporting occurred in only $3 \%$ of the cases with multiple spells of incapacity to work, yet it was present in $28 \%$ of those with only one spell of sick leave listing because of low back pain. The duration of the episode as well 
as certain personality traits were associated with accuracy of recall. A population study on the lifetime incidence of low back pain in a sample of 40-47 year old Swedish men, ${ }^{88}$ identified $27 \%$ among those without an interview history of low back pain who had actually claimed sick benefit because of low back pain during the preceding 22 years. Walsh et $a l^{67}$ used a self administered questionnaire to obtain data on a history of back pain and associated disability in a sample of 225 men and women. Over a 12 month period they observed good agreement of data on whether subjects had ever suffered back pain or had consulted a general practitioner because of back pain. Other variables, for example, on the speed of onset of symptoms, presence or absence of sciatica, and disability, however, were less reliably measured.

\section{Summary}

Back pain is a very common and extensively studied type of pain. It can be used as a paradigmatic condition in order to identify conceptual and methodological problems of pain surveys in general. Because of the complexity of any pain experience, surveys for pain disorders should be based on a multidimensional pain model. The limited applicability of diagnostic procedures in epidemiological studies or genuine non-specificity of pain states, or both, in surveys may result in a considerable proportion of cases without an identifiable pathophysiological basis.

Classification, staging, and grading are related but different operations which have to be distinguished clearly. While classification could employ "manifestational" or pathogenetic concepts, staging and grading are usually based on various aspects of pain perception: regional distribution, pain intensity, temporal characteristics, sensory qualities and characteristics of cognitive and affective appraisal. Description of temporal development (staging) should consider different levels of chronicity. For grading, explicit a posteriori methods are preferable to variable screening questions with an implicit grading.

The typical coincidence of site specific pains (for example, back pain) with pain at other sites or other symptoms, or both, indicates that strictly "local" concepts may be misleading. More emphasis should be placed on the identification of complex complaint syndromes.

Finally, a multitude of factors may negatively affect the reliability and validity of data collected in pain surveys. Recall biases seem to deserve special attention.

The authors are greatly indebted to Alan J Silman for his encouragement and support in writing and editing this paper.

1 Crook J, Rideout E, Browne G. The prevalence of pain complaints in a general population. Pain 1984:18:299314.

2 Taylor H, Curran NM. The Nuprin pain report. New York: Louis Harris and Associates, 1985.

3 Von Korff M, Dworkin SF, Le Resche L, Kruger A. An epidemiologic comparison of pain complaints. Pain 1988; 32:173-83.

4 Brattberg G, Thorslund M, Wikman A. The prevalence of pain in a general population. The results of a postal survey in in a 1989;37:215-22.

5 Kolm Ergebnisse einer bevölkerungsepidemiologischen Studie. Der Schmerz 1991;5:208-13.
6 James FR, Large RG, Bushnell JA, Wells JE. Epidemiology of pain in New Zealand. Pain 1991;44:279-83.

7 Croft P, Rigby AS, Boswell R, Schollum J, Silman A. The prevalence of chronic widespread pain in the general population. $f$ Rheumatol 1993;20:710-63.

8 Lawrence JS. Disc degeneration. Its frequency and relationship to symptoms. Ann Rheum Dis 1969;28:121-37.

9 Drury TF. Problems of meaning and measurement in cross sectional interview surveys of chronic pain in the adult population. In: CR Chapman, JD Loeser, eds. Issues in pain measurement. New York: Raven Press, 1989:489-518.

10 Raspe H. Back pain. In: AJ Silman, MC Hochberg, eds. Epidemiology of the rheumatic diseases. Oxford: Oxford University Press, 1993:330-74

11 IASP. Classification of chronic pain. Descriptions of chronic pain syndromes and definition of pain terms. Pain (Supp1 3): 1986.

12 Loeser JD. Concepts of Pain. In: M Stanton-Hicks, RA Boas, eds. Chronic low back pain. New York: Raven Press, 1982: 145-8.

13 Hildebrandt J. Diagnostik und Klassifikation chronischer "idiopathischer" Rückenschmerzen. Göttingen: Fachbereich Medezin der Universität (Habilitationsschrift) 1987.

14 Anderson JAD. Problems of classification of low-back pain Rheumatology and Rehabilitation 1977;16:34-6.

15 Nachemson AL, Andersson GBJ. Classification of low-back pain. Scand F Work Environ Health 1982;8:134-6.

16 Von Korff MR, Dworkin SF. Problems of measuring pain by survey: the classification of chronic pain in field research. In: CR Chapman, JD Loeser eds. Issues in pain management. New York: Raven Press, 1989:519-33.

17 Coste J, Paolaggi JB, Spira A. Classification of nonspecific low back pain. I. Psychological Involvement in low back pain. Spine 1992;17:1028-37.

18 Coste J, Paolaggi JB, Spira A Classification of nonspecific low back pain. II. Clinical diversity of organic forms. Spine 1992;17:1038-42.

19 LaRocca H. A taxonomy of chronic pain syndromes. Spine 992;17:S344-55.

20 Talo S, Rytökoski U, Puukka P. Patient classification, a key to evaluate pain treatment: a psychological study in chronic low back pain patients. Spine 1992;17:998-1011.

21 Turk DC, Rudy TE. Toward an empirically derived taxonomy of chronic pain patients: integration of psychological assessment data. $\mathcal{F}$ Consult Clin Psychol 1988; 56:233-8. 22 Turk DC, Rudy TE. The robustness of an empirically
derived taxonomy of chronic pain patients. Pain 1990;43: 27-35.

23 Main CJ, Wood PLR, Hollis S, Spanswick CC, Waddell G. The distress and risk assessment method. A simple patient classification to identify distress and evaluate the risk of poor outcome. Spine 1992;17:42-52.

24 Main CJ. The modified somatic perception questionnaire (MSPQ). $₹$ Psychosom Res 1983;27:503-14.

25 Waddell G, McCulloch JA, Kummel E, Venner RM. Nonorganic physical signs in low-back pain. Spine 1980;5: $117-25$.

26 Waddell G, Main CJ, Morris EW, DiPaola M, Gray ICM. Chronic low-back pain, psychologic distress, and illness behavior. Spine 1984;9:209-13.

27 Dougados M, Van Der Linden S, Juhlin R, et al. The European Spondylarthropathy Study Group preliminary criteria for the classification of spondylarthropathy. Arthritis Rheum 1991;34:1218-27.

28 Wolfe F, Smythe HA, Yunus MB, et al. The American College of Rheumatology 1990 criteria for the classification of fibromyalgia. Arthritis Rheum 1990;33:160-72.

29 Coste J, Spira A, Ducimetiere P, Paolaggi J. Clinical and psychological diversity of non-specific low-back pain. A new approach towards the classification of clinical subgroups. F Clin Epidemiol 1991;44:1233-45.

30 Frymoyer JW. Back pain and sciatica. New Engl f Med 1988; 318:291-300.

31 Kuorinka I, Jonsson B, Kilbom A, et al. Standardised Nordic questionnaires for the analysis of musculoskeletal sympquestionnaires for the analysis of musculos

32 Toomey TC, Gover VF, Jones BN. Spatial distribution of pain: a descriptive characteristics of chronic pain. Pain pain: a descriptive

33 Margolis RB, Chibnall JT, Tait RC. Test-retest reliability of the pain drawing instrument. Pain 1988;33:49-51.

34 Mann III NH, Brown MD, Hertz DB, Enger I, Tompkins $\mathrm{J}$. Initial-impression diagnosis using low-back pain patient pain drawings. Spine 1993;18:41-53.

35 Waddell G, Bircher M, Finlayson D, Main CJ. Symptoms and signs: physical disease or illness behaviour? $B M \mathcal{F}$ 1984;289:739-41.

36 Uden A, Aström M, Bergenudd H. Pain drawings in chronic back pain. Spine 1988;13:389-92.

37 Chan CW, Goldman S, Ilstrup DM, Kunselman AR, O'Neil PI. The pain drawing in Waddell's nonorganic physical signs in chronic low-back pain. Spine 1993;18:1717-22.

38 McNeill TW, Sinkora G, Leavitt F. Psychologic classification of low-back pain patients: a prognostic tool. Spine 1986; 11:955-9.

39 Ransford AO, Cairns D, Mooney V. The pain drawing as an aid to the psychologic evaluation of patients with lowback pain. Spine 1976;1:127-34.

40 Ryden O, Lindal E, Uden A, Hansson SB. Differentiation of back pain patients using a pain questionnaire. Scand $\mathcal{F}$ Rehab Med 1985;17:155-61.

41 Margolis RB, Tait RC, Krause SJ. A rating system for use with patient pain drawings. Pain 1986;24:57-65. 
42 Von Baeyer CL, Bergstrom KJ, Brodwin MG, Brodwin SK. Invalid use of pain drawings in psychological screening of back pain patients. Pain 1983;16:103-7.

43 Ginzburg BM, Merskey H, Lau CL. The relationship between pain drawings and the psychological state. Pain 1988;35:141-6.

44 Hildebrandt J, Franz CE, Choroba-Mehnen B, Temme M The use of pain drawings in screening for psychological involvement in complaints of low-back pain. Spine 1988 13:681-5.

45 Bergenudd $\mathrm{H}$, Johnell $\mathrm{O}$. Somatic versus nonsomatic shoulder and back pain experience in middle age in relation to glutamyltransferase, occupational workload, and psyglutamyltransferase, occupational work
chosocial factors. Spine 1991;16:1051-5.

46 Reading AE. A comparison of pain rating scales. 7 Psychosom Res 1980;24:119-24.

47 Jensen MP, Karoly P, Braver S. The measurement of clinical pain intensity: a comparison of six methods. Pain 1986 27:117-26

48 Duncan GH, Bushnell MC, Lavigne GJ. Comparison of verbal and visual analogue scales for measuring the intensity and unpleasantness of experimental pain. Pain 1989; 37:295-303.

49 Ferraz MB, Quaresma MR, Aquino LR L, Atra E, Tugwell $\mathrm{P}$, Goldsmith $\mathrm{CH}$. Reliability of pain scales in the assessment of literate and illiterate patients with rheumatoid arthritis. F Rheumatol 1990;17:1022-4.

50 Von Korff M, Dworkin SF, Le Resche L. Graded chronic pain status: an epidemiologic evaluation. Pain 1990;40 279-91.

51 Raspe H, Kohlmann T. Rückenschmerzen - eine Epidemie unserer Tage? Deutsches Ärzteblatt 1993;90:2920-5.

52 Melzack R, Torgerson WS. On the language of pain. $A n$ esthesiology 1971;34:50-9.

53 Melzack R. The McGill pain questionnaire: major propertie and scoring methods. Pain 1975;1:277-99.

54 Melzack R. The short-form McGill pain questionnaire. Pain 1987;30:191-7.

55 Holroyd K, Holm J, Keefe F, et al. A multi-center evaluation of the McGill pain questionnaire: results from more than 1700 chronic pain patients. Pain 1992;48:301-11.

56 Rosenstiel AK, Keefe FJ. The use of coping strategies in chronic low back pain patients: relationship to patient chronic low back pain patients: relationship to patient charact

57 Jensen M, Turner J, Romano J, Karoly P. Coping with chronic pain: a critical review of the literature. Pain 1991 47:249-83.

58 Flor $\mathrm{H}$, Turk DC. Chronic back pain and rheumatoid arthritis: predicting pain and disability from cognitive variables. $\mathcal{F}$ Behavioral Med 1988;11:251-65.

59 Main CJ, Waddell GA. Comparison of cognitive measures in low back pain: statistical structure and clinical validity at initial assessment. Pain 1991;46:287-98.

60 Toomey TC, Mann JD, Abashian S, Thompson-Pope S. Relationship between perceived self-control of pain, pain Relationship between perceived self-control of pain,

61 Quebec Task Force on Spinal Disorders. Scientific approach to the assessment and management of activity-related spinal disorders. Spine 1987;12(Suppl 1):51-9.

62 Bonica JJ. Definitions and taxonomy of pain. In: JJ Bonica, ed. The management of pain. 2nd ed. Vol I. Philadelphia Lea Febiger, 1990:18-27.

63 Waddell GA. New clinical model for the treatment of lowback pain. Spine 1987;12:632-44.

64 Chan S, Ryan MD. Low-back pain in school children in the fifth and sixth grade. Fournal of Orthopaedic Rheumatolog 1992;5:43-8.
65 Magni G, Marchetti M, Moreschi C, Merskey H, Rigatti Luchini S. Chronic musculoskeletal pain and depressive symptoms in the national health and nutrition examination I epidemiologic follow-up study. Pain 1993;53:163-8.

66 Deyo RA, Tsui-Wu Y. Descriptive epidemiology of lowback pain and its related medical care in the United States. Spine 1987;12:264-8.

67 Walsh K, Cruddas $M$, Coggon D. Low back pain in eigh areas of Britain. $\mathcal{F}$ Epidemiol Community Health 1992;46: 227-30.

68 Biering-Sorensen F. Low back trouble in a general population of 30-, 40-, 50-, and 60-year-old men and women. Dan Med Bull 1982;29:289-99.

69 Croft PR, Rigby AS. Socioeconomic influences on back problems in the community. $\mathcal{F}$ Epidemiol Community Health 1994;48:166-70.

70 Waddell G, Main CJ. Assessment of severity in low-back disorders. Spine 1984;9:204-8.

71 Von Korff M, Ormel J, Keefe FJ, Dworkin SF. Grading the severity of chronic pain. Pain 1992;50:133-49.

72 Dworkin SF, Von Korff M, LeResche L. Multiple pains and psychiatric disturbance. Arch Gen Psychiatr 1990;47: 239-44.

73 Valkenburg HA, Haanen HCM. The epidemiology of low back pain. In: AA White, SL Gordon eds. Symposium on idiopathic low back pain. St Louis: Mosby, 1982:9-22.

74 Raspe H, Wasmus A, Greif G, Kohlmann T, Kindel P Mahrenholtz M. Rückenschmerzen in Hannover. Aktuelle Rheumatologie 1990;15:32-7.

75 Raspe H, Kohlmann T, Deck R. Back pain as a chronic systemic disorder: results of two population surveys [abstract]. Arthritis Rheum 1993 12(suppl):S234.

76 von Zerssen D, Koeller D. Die Beschwerdenliste. Manual. Weinheim: Beltz Test Gesellschaft, 1976.

77 Hadler NM. Regional back pain. New Engl f Med 1986; 315:1090-2.

78 Bradburn NM. Response effects. In: PH Rossi, JD Wright, AB Anderson, eds. Handbook of survey research. San Diego: Academic Press, 1983:289-328.

79 Lessler JT. Measurement error in surveys. In: CF Turner E Martin, eds. Surveying subjective phenomena. Vol 2. New York: Russell Sage Foundation, 1984:405-40

80 Groves RM. Survey errors and survey costs. New York: John Wiley, 1989.

81 Biemer PP, Groves RM, Lyberg LE, Mathiowetz NA, Sudman S, eds. Measurement errors in surveys. New York: John Wiley, 1991.

82 Fienberg SE, Loftus EF, Tanur JM. Recalling pain and other symptoms. Milbank Memorial Fund Quarterly; Healt and Society 1985;63:582-97.

83 Coughlin SS. Recall bias in epidemiologic studies. $f$ Clin Epidemiol 1990;43:87-91.

84 Means B, Nigam A, Zarrow M, Loftus EF, Donaldson MS Autobiographical memory for health-related events. Hy-
attsville, MD: US Department of Health and Human Services (DHHS Publication No (PHS) 89-1077), 1989.

85 Brewer MB, Dull VT, Jobe JB. Social cognition approach to reporting chronic conditions in health surveys. Hyattsville, MD: US Department of Health and Human Services (DHHS Publication No (PHS) 89-1078), 1989

86 Salovey P, Jobe JB, Willis GB, et al. Response errors and bias in the recall of chronic pain. American Statistical Association 1989 Proceedings of the Section on Survey Research Methods, 1989:413-20.

87 Westrin C. The reliability of auto-anamnesis. Scand f Soc Med 1974;2:23-35.

88 Svensson H, Andersson GBJ. Low back pain in forty to forty-seven year old men. I. Frequency of occurrence and impact on medical services. Scand f Rehab Med 1982;14: 47-53. 